\title{
Activation and regulation of chemokines in allergic airway inflammation
}

\author{
N.W. Lukacs, R.M. Strieter, S.W. Chensue, ${ }^{\dagger}$ and S.L. Kunkel \\ Departments of Pathology and Internal Medicine, *Division of Critical Care and Pulmonary Medicine, University of \\ Michigan Medical School and +Department of Pathology, Veterans Affairs Medical Center Ann Arbor, Michigan \\ 48109-0602
}

\begin{abstract}
Allergic airway inflammation is characterized by peribronchial eosinophil accumulation within the submucosa surrounding the airway. The initial induction of immunoglobulin E (IgE)-mediated mast cell degranulation, up-regulation of adhesion molecules, and the production of inflammatory and chemotactic cytokines, leading to the infiltration of specific leukocyte subsets, is orchestrated in a sequential manner. The activation and degranulation of local mast cell populations is an immediate airway response mediated both by antigen-specific, surface bound IgE and by cytokine-induced activational pathways. Subsequently the infiltration and activation of effector leukocytes (neutrophils and eosinophils) mediated by the persistant activation of allergen-specific $T$ cells leads to pathological manifestations within the lung and airway. The development of appropriate animal models to dissect the critical mechanisms involved in antigen-induced airway pathology is crucial for the development of efficacious therapies. We have utilized a model of allergic airway inflammation induced by intratracheal challenge with parasite (Schistosoma mansoni) egg antigen in presensitized mice. This model has proven useful in the assessment of eosinophil recruitment and has identified key cytokines involved in leukocyte elicitation. These cytokines include interleukin-4 and tumor necrosis factor, which appear to act as early response mediators, as well as C-C chemokines, macrophage inflammatory protein-1a, and RANTES, which act directly on eosinophil recruitment. In addition, we have found that both C-X-C and C-C chemokines are expressed in pulmonary-derived mast cells, suggesting an important contribution to leukocyte responses in the allergic airway. J. Leukoc. Biol. 59: 13-17; 1996.
\end{abstract}

Key Words: allergy · asthma

\section{INTRODUCTION}

Allergic pulmonary diseases affect a significant proportion of the population worldwide and include disorders such as asthma, pulmonary eosinophilia, and bronchopulmonary mucomycosis [1]. The long-term pathological effects of asthma have been attributed, in part, to infiltrating leukocytes that surround the bronchus and infiltrate into the airway [2-4]. The immune response associated with asthma has been described as having histopathological features of a chronic cell-mediated immune reaction, characterized by the infiltration of the bronchial mucosa with neutrophils, basophils, eosinophils, macrophages, and lymphocytes [2]. Eosinophils have been reported to be the primary cell responsible for the induction of bronchial mucosal injury and are thought to contribute to the bronchial obstruction associated with the asthmatic response $[1,2,3$, 4]. In atopic asthmatic inflammation, a concomitant production of Th2 cell type cytokines interleukin [(IL)-4, IL5] has been observed, which correlates with disease intensity and eosinophil infiltration [5-13]. In animal models, the depletion of $\mathrm{CD}^{+}{ }^{+} \mathrm{T}$ cells results in an abrogated eosinophilia and a reduction in airway hyperreactivity [14]. Thus it appears that $T$ cells with a Th2 cytokine phenotype mediate and maintain allergic airway responses, such as in atopic asthma.

The elicitation of leukocyte subsets has been attributed with the production of several different chemotactic factors. Leukotriene $\mathrm{B}_{4}$ (LTB-4), platelet-activating factor (PAF), and C5a have been defined as nonspecific chemoattractants responsible for leukocyte recruitment, with the ability to elicit not only neutrophils, but also mononuclear cells and eosinophils. Recently, several laboratories have identified specific neutrophil, mononuclear, and eosinophil chemotactic cytokines (chemokines). These potent chemoattractants are divided into two distinct supergene families, C-X-C and C-C, designated by the position of the first two cysteine amino acid residues $[15,16]$. The C-X-C family of chemokines is primarily chemotactic for neutrophils and is typified by IL-8. The C-C family of chemokines is primarily chemotactic for mononuclear

Abbreviations: IgE, immunoglobulin E; IL, interleukin; $\mathrm{LTB}_{4}$, leukotriene $\mathrm{B}_{\mathbf{4}}$; PAF, platelet-activating factor; MCP-1,2,3, monocyte chemoattractant protein-1,2,3; MIP-1 $\alpha$, macrophage inflammatory protein-1 $\alpha$; TNF, tumor necrosis factor; SEA, Schistosoma mansoni egg antigen.

Reprint requests: N.W. Lukacs, Department of Pathology, University of Michigan, 1301 Catherine/Box 0602, University of Michigan Medical Center, Ann Arbor, MI 48109-0360.

Received July 31, 1995; revised August 25, 1995; accepted August 28, 1995. 
phagocytes, lymphocytes, and eosinophils and contains closely related proteins: monocyte chemoattractant protein-1,2,3 (MCP-1,2,3), macrophage inflammatory protein$1 \alpha$ (MIP-l $\alpha$ ), and RANTES [15]. The C-C family members are of particular interest in the allergic response, since there appears to be a strong correlation with the expression of C-C chemokines and chronic inflammatory diseases [16]. In particular, MIP-1 $\alpha$ and RANTES may be important in the allergic airway response for several reasons. These proteins have been shown to be chemotactic for monocytes, differentially chemotactic for lymphocyte subsets [17-19], and more importantly, chemotactic for eosinophils in vitro [20]. More recently, a novel C-C chemokine, MCP-3, has been identified as an extremely potent eosinophil chemoattractant protein and therefore implicated in allergic responses [21]. In addition, a novel C-C chemokine, eotaxin, was detected by use of an allergic airway model in the guinea pig [22]. The identification of these eosinophil chemoattractant proteins may serve as important targets in inflammation for the control of allergic airway diseases.

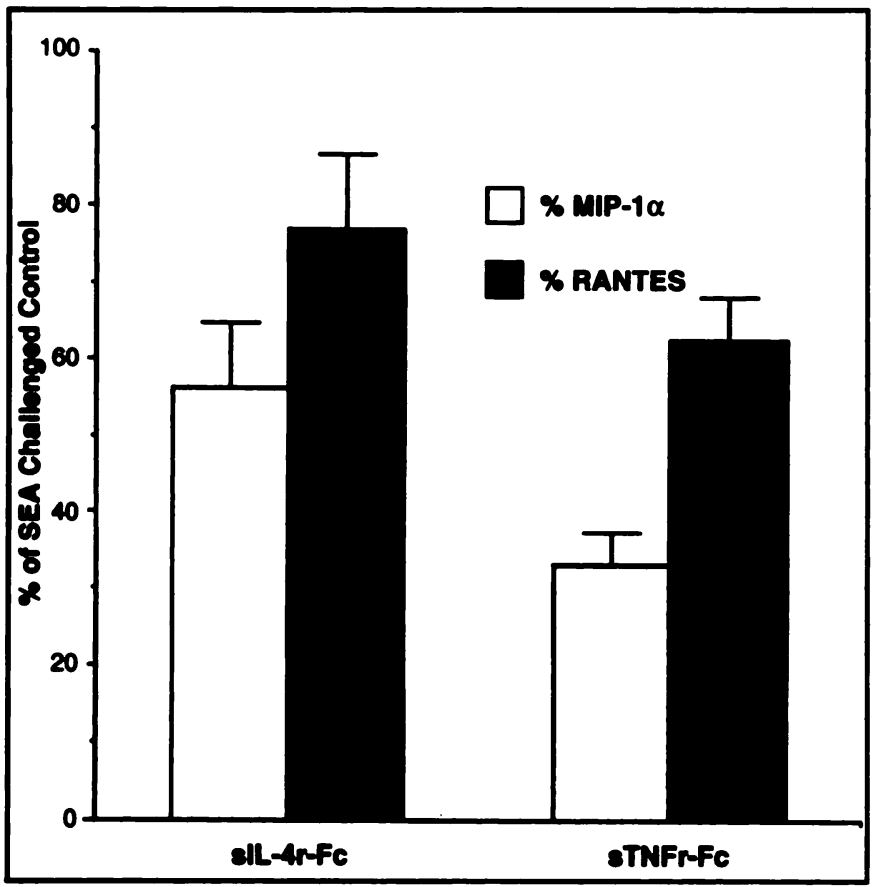

Fig. 1. Soluble IL-4 and TNF receptor constructs (provided by Immunex Corp., Seattle, WA) decrease production of eosinophil chemotactic cytokines, MIP- $1 \alpha$ and RANTES. Mice were treated with soluble IL -4 and TNF receptor constructs $2 \mathrm{~h}$ before an intratracheal challenge with SEA. Lungs were removed and homogenated at $8 \mathrm{~h}$ post-challenge, time of peak chemokine production. RANTES and MIP-l $\alpha$ levels were measured in the samples by specific enzyme-linked immunosorbent assays. Data is presented as percent of control antibody treated SEA control and represents the mean $\pm S E$ from 5 mice in each group.
Table 1. Immunolocalization of Chemokines in Pulmonary-Derived Mast Cells

\begin{tabular}{lc} 
Chemokine & Intensity of Staining \\
\hline C-X-C & $+/$ \\
MIP-2 & + \\
ENA-78 & \\
C-C & + \\
MIP-1 $\alpha$ & + \\
MCP-1 & +++ \\
RANTES & +
\end{tabular}

\section{EARLY RESPONSE CYTOKINES IN ALLERGIC EOSINOPHILIC AIRWAY INFLAMMATION}

The release of early response cytokines, IL-1 and tumor necrosis factor (TNF), during a response is crucial for induction of selectin and adhesion molecule expression, the initiation of cytokine cascades, the up-regulation of specific chemokines, and the recruitment of leukocyte subsets. The contribution of IL-1 and TNF to allergic eosinophil recruitment has been verified in vivo through the use of IL-l receptor antagonist protein in a guinea pig model of eosinophilic airway inflammation [23] and by soluble TNF receptor treatment in our murine model of eosinophilic airway inflammation [24]. Increases in TNF production were observed early during allergen challenge, between 1 and $8 \mathrm{~h}$. Furthermore, when TNF was neutralized in vivo, both neutrophil $(\sim 40 \%)$ and eosinophil $(\sim 70 \%)$ recruitment were significantly altered [24]. In these latter studies, inhibition of either IL-1 or TNF activational pathways significantly decreased the eosinophilic migration into the airway.

In addition to IL-1 and TNF, IL-4 released by both mast cells $[25,26]$ and antigen-stimulated Th2 cells $[10,11]$ can up-regulate VCAM-1 expression on vascular endothelium [27] and further contribute to the lymphocyte, monocyte, and eosinophil extravasation. Given the correlation of Th2 type cytokine (IL-4) production and eosinophilic inflammation in airways of asthmatics, this latter pathway may constitute a significant contribution to the overall leukocyte recruitment. This cascade has been verified in animal models of allergic airway eosinophilia. We have previously detected substantial levels of IL-4 in the BAL fluid of mice by 8-24 $\mathrm{h}$ post intratracheal challenge with allergen [28]. In this Schistosoma mansoni egg antigen (SEA) model, mice treated with antibodies to IL-4 demonstrated a significant decrease in leukocyte recruitment, which nearly abrogated the eosinophilic airway inflammation. These data suggested that the early production of IL-4. may be critical to development of an allergic eosinophilic response. In separate experiments, using an ovalbumin-induced airway eosinophil model, IL-4-deficient mice demonstrated a significantly attenuated inflammatory airway response [29]. These animal models provide initial evi- 
Table 2. Neutralization of ENA-78 Blocks Mast Cell Sonicate-Induced Neutrophil Infiltration Into the Airways of Normal Mice and During Allergen Challenge in Allergic Mice

\begin{tabular}{lcc} 
& \multicolumn{2}{c}{ \%o Neutrophil infiltration } \\
\cline { 2 - 3 } Antibody treatment & Mast cell sonicate $^{1}$ & Allergen model $^{2}$ \\
\hline Control Ab & $87.2 \pm 2.9$ & $75.3 \pm 5.0$ \\
anti-ENA-78 & $46.4 \pm 7.9$ & $48.3 \pm 6.4$ \\
\hline
\end{tabular}

${ }^{1}$ Mast cells $2 \times 10^{6}$ were sonicated, and the cell-free supernatant $(25 \mu l)$ combined with control or anti-ENA-78 antobody (1:20 dilution) was injected intratracheally into normal mice. One-milliliter BAL fluid samples were examined $4 \mathrm{~h}$ poet-eonicate injection.

${ }^{2}$ Control or anti-ENA-78 antibody was injected intraperitoneally into allergic mice $2 \mathrm{~h}$ prior to allergen challenge. One milliliter BAL fluid smaples were taken $8 \mathrm{~h}$ poet-challenge, the time of peak neutrophil migration.

dence that Th2 (IL-4, IL-5) type inflammation observed in allergic airway responses have a significant relationship to the subsequent elicitation of leukocyte subpopulations. Although TNF and IL-4 are not by themselves chemotactic, they can up-regulate the production of chemotactic factors and adhesion molecules and appear to have complimentary critical roles in allergic airway inflammation.

\section{C-C chemokines in allergic eosinophilic airway inflammation}

The production of chemokines during asthmatic responses in humans may contribute specifically to the influx of eos- inophils. Eosinophils have been implicated as a major effector cell inducing airway injury and subsequent late phase reactivity in asthmatics $[1,2]$. A number of the C-C chemokines appear to preferentially recruit human eosinophils in vitro, including RANTES, MIP-1 $\alpha$, and MCP-3 $[20,21]$. In addition, IL-8, a C-X-C chemokine, also appears to have some activity on eosinophil recruitment [30]. The measurement of MIP-1 $\alpha$ [31] and RANTES protein in lung homogenates or BAL fluids has demonstrated increased production during the development of the eosinophilic response, peaking between 8 and 48 h post airway allergen challenge. The cellular source of the two chemokines was determined by immunohistochemical localization. MIP-1 $\alpha$ appears to be produced by macrophages and airway epithelial cells [31], whereas RANTES appears to be produced primarily by type II epithelial cells within the lung. In addition, the production of both MIP-1 $\alpha$ and RANTES was significantly decreased in lung homogenates when either IL-4 or TNF were neutralized in vivo by use of soluble cytokine receptors (Fig. 1). These studies indicate that these early response cytokines up-regulated eosinophil recruitment, at least in part, via induction of chemokine production. Furthermore, when either MIP-1 $\alpha$ or RANTES was neutralized in vivo, a significant decrease in airway eosinophilia was observed with both anti-MIP-1 $\alpha$ $(>50 \%)$ [34] and anti-RANTES $(>60 \%)$ antibody administration, indicating that multiple chemokines contribute to the recruitment of eosinophils. In addition, when lung histology of the control, anti-MIP-l $\alpha$, and anti-RANTES antibody-treated animals was examined there was still a

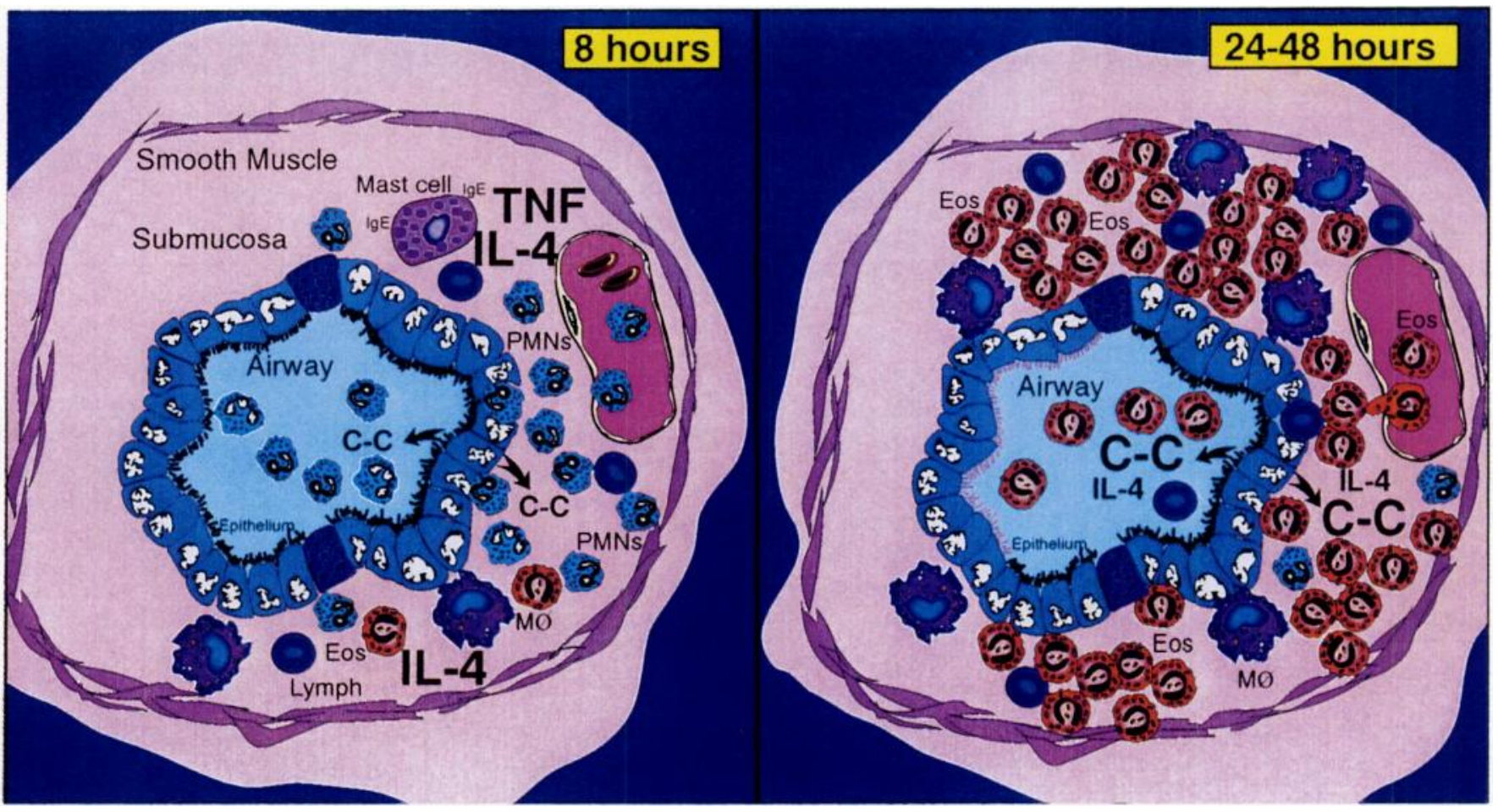

Fig. 2. The progression of allergen-specific airway inflammation in sensitized mice. The initiation of the allergic airway response likely entails multiple mechanisms of activation, including antigen-specific IgE-mediated mast cell degranulation and T lymphocyte activation. These allergen specific events lead to the production of multiple inflammatory (TNF- $\alpha$, IL-4) and chemotactic (MIP-1 $\alpha$, RANTES) cytokines that probably facilitate leukocyte recruitment and airway reactivity. 
considerable peribronchial mononuclear cell infiltrate. However, in these same mice there was a paucity of eosinophils present in the lung compared with control antibody-treated mice. Interestingly, passive immunization with anti-MCP-1 did not reduce the influx of eosinophils into the airway, thus demonstrating chemokine specificity for the eosinophilic response. These latter observations may begin to outline that $\mathrm{C}-\mathrm{C}$ chemokines, which have overlapping functions, may play specific roles in particular types of inflammation (i.e., eosinophil but not mononuclear cell recruitment). The use of the SEA animal model, which has many of the attributes of human asthma, begins to outline the specific role that $\mathrm{C}-\mathrm{C}$ chemokines play in allergic airway inflammation, leading to eosinophil recruitment.

\section{Ainway-derived mast cells contain C-X-C and C-C chemokines}

Mast cell activation likely comprises a major role in the initiation of the airway response during allergen lung challenge. Immunoglobulin E (IgE)-mediated activation of mast cells induces immediate degranulation and release of inflammatory mediators, including histamine, seratonin, PAF, leukotrienes $\left(\mathrm{LTB}_{4}, \mathrm{C}_{\mathbf{4}}, \mathrm{D}_{\mathbf{4}}\right.$, and $\left.\mathrm{E}_{4}\right)$, prostaglandin $D_{2}$, as well as several other inflammatory mediators [32]. These mediators can induce immediate responses, such as vascular permeability, bronchoconstriction, edema, and mucus secretion, all of which contribute to decreased pulmonary function [32]. In addition, these early mediators have the ability to induce the recruitment of additional leukocytes into the lung as well as activate local cell populations for the production of additional cytokines. Other cytokines can also be produced by mast cells. Recent investigations have identified the production of IL-1, IL-4, and TNF upon mast cell degranulation. Thus mast cells are a primary source of potent early response cytokines capable of initiating the expression of adhesion molecules and cytokine cascades, leading to increased leukocyte recruitment [33]. Early studies described mast cell-derived neutrophil and eosinophil chemotactic factors capable of mediating the leukocyte recruitment responses in a nonspecific manner.

More recently, mast cells have been identified as a source of several chemotactic cytokines, chemokines, which possess the ability to specifically recruit particular leukocyte populations. Our laboratory has isolated and grown airway mast cell populations in vitro using specific growth factors, stem cell factor, and IL-3. These investigations have identified the presence of several chemokines in pulmonary mast cell populations. Table 1 summarizes the immunohistochemical and/or immunogold localization of chemokines in pulmonary mast cell lines. These investigations have identified the mast cell as a significant source of specific chemokines, MIP-1 $\alpha$, MCP-1, RANTES, and ENA-78, with marginal staining of MIP-2 (a functional murine homolog of IL-8). These findings are in agreement with early investigations examining the expression of chemokines in human mast cell populations [34]. To fur- ther investigate the role of mast cell-derived chemokines in airway responses, sonicates from pulmonary mast cell Knes were administered intratracheally to normal mice. When leukocyte infiltration was examined in the airway by BAL at $4 \mathrm{~h}$ post-intratracheal mast cell sonicate administration, a predominant neutrophil infiltration was observed. The neutrophils constituted $80-90 \%$ of the infiltrate. If the mast cell sonicates were preincubated with control, anti-ENA-78, or anti-MIP-2 antibodies, only antiENA-78 significantly reduced the neutrophil infiltration (Table 2). To examine the role of ENA-78 in allergic airway inflammation we utilized the SEA-induced mouse model of allergic airway inflammation. When allergic mice were treated with control, anti-ENA-78, or anti-MIP-2 antibodies before intratracheal SEA (allergen) challenge, only anti-ENA-78 significantly inhibited neutrophil accumulation. These studies indicated that ENA-78 was a primary mast cell-derived neutrophil chemotactic factor that is likely released upon allergen challenge inducing neutrophil infiltration. Further studies will examine the role of mast cell-derived C-C chemokines for mononuclear and eosinophil recruitment in this allergic mouse model. Altogether, these studies suggest that mast cells have the ability to induce cytokine-mediated leukocyte infiltration upon activation and degranulation and constitute a major effector cell during allergic responses.

\section{Summary}

The elucidation of mechanisms involved in leukocyte recruitment during an allergic airway response is paramount for the understanding and treatment of allergic airway diseases such as asthma. It appears that a sequential production of early response cytokines, IL-4 and TNF, leads to the subsequent production of eosinophil-specific chemokines, MIP-l $\alpha$ and RANTES (summarized in Fig. 2). Neutralization studies in experimental models have identified all four of these cytokines as having a significant role in eosinophil accumulation in vivo. In addition, the mast cell, which is primarily activated during allergic responses, produces both neutrophil and eosinophil-specific chemokines and therefore constitutes an important source of chemotaxins during allergic responses. The identification of specific target molecules and their cellular sources may lead to development of novel therapeutic applications that can be tested for efficacy and function in animal models of inflammation.

\section{ACKNOWLEDGMENTS}

This work was supported in part by National Institutes of Health grants HLO2401, HL31693, HL35276, AI36302, and by the American Lung Association.

\section{REFERENCES}

1. Kay, A.B. The eosinophil. Pulmonary diseases and disonders, 2nd ed. (A.P. Fishman, ed) McGraw-Hill, New York, 1988, p. 599-606. 
2. Kay, A.B., Corrigan, C.J. (1992) Asthma, eosinophils, and neutrophils. Br. Med. Bull. 48, 51-64.

3. Gleich, G.J. (1986) The eosinophilic leukocyte: structure and function. Adv. Immunol. 39, 177-253.

4. Wang, J.M., Sherry, B., Fivash, M.J., Kelvin, D.J., Oppenheim, J.J. (1993) Human recombinant macrophage inflammatory protein- $1 \alpha$ and $\beta$ and monocyte chemotactic and activating factor utilize common and unique receptors on human monocytes. J. Immunol. 150, 3022-3029.

5. Corrigan, C.J., Kay, A.B. (1992) Asthma. Role of T-lymphocytes and lymphokines. Br. Med. Bull. 48, 72-84.

6. Corrigan, C.J., Kay, A.B. (1992) T cells and cosinophils in the pathogenesis of asthma. Immunol. Today 13, 501-507.

7. Del Prete, G. (1992) Human Thl and Th2 lymphocytes: their role in the pathophysiology of atopy. Allergy 47, 450-455.

8. Gratziou, C., Carroll, M., Walls, A., Howarth, P.H., Holgate, S.T. (1992) Early changes in $\mathrm{T}$ lymphocytes recovered by bronchoalveolar lavage after local allergen challenge of asthmatic airways. Am. Rev. Respir. Dis. 145, 1259-1264.

9. Kay, A.B. (1991) T lymphocytes and their products in atopic allergy and asthma. Int. Arch. Allergy Appl. Immunol. 94, 189-193.

10. Robinson, D.S., Hamid, Q., Ying, S., Tricopoulos, A., Barkans, J., Bentley, A.M., Corrigan, C., Durham, S.R., Kay, A.B. (1992) Predominant TH2-like bronchoalveolar T-lymphocyte population in atopic asthma. N. Engl. J. Med. 326, $298-304$.

11. Romagnani, S., Maggi, E., Parronchi, P., Macchia, D., Piccinni, M.P., Ricci, M. (1991) Increased numbers of Th2-like $\mathrm{CD4}^{+} \mathrm{T}$ cells in target organs and in the allergen-specific repertoire of allergic patients. Possible role of IL-4 produced by non-T cells. Ins. Arch. Allergy Appl. Immunol. 94, 133-136.

12. Walker, C., Virchow, J.C., Jr., Bruijnzeel, P.L., Blaser, K. (1991) T cells and asthma. II. Regulation of eosinophilia of asthma by $\mathrm{T}$ cell cytokines. Int. Anch. Allergy Appl. Immunol. 94, 248-250.

13. Zhang, X., Polla, B., Hauser, C., Zubler, R.H. (1992) T cells from atopic individuals produce IgE-inducing activity incompletely blocked by anti-interleukin-4 antibody. Eur. J. Immunol. 22, 829-833.

14. Gavett, S.H., Chen, X., Finkleman, F., Wills-Karp, M. (1994) Depletion of murine $\mathrm{CD}^{+}{ }^{+} \mathrm{T}$ lymphocytes prevents antigen-induced airway hyperreactivity and pulmonary eosinophilia. Am. J. Respir. Cell Mol. Biol. 10, 587-593.

15. Schall, T.J. (1991) Biology of the RANTES/SIS cytokine family. Cytokine 3, 165-183.

16. Oppenheim, J.J., Zachariae, C.O.C., Mukaida, N., Matsushima, K. (1991) Properties of the novel proinflammatory "intercrine" cytokine family. Annu. Rev. Immunol. 9, 617.

17. Davatelis, G., Tekamp-Olson, P., Wolpe, S.D., Hermsen, K., Luedke, C. Gallegos, C., Coit, D., Merryweather, J., Cerami, A. (1989) Cloning and characterization of a cDNA for murine macrophage inflammatory protein (MIP), a novel monokine with inflammatory and chemokinetic properties. J. Exp. Med. 167, 1939-1944.

18. Taub, D.D., Conlon, K., Lloyd, A.R., Oppenheim, J.J., Kelvin, D.J. (1993) Preferential migration of activated $\mathrm{CD4}^{+}$and $\mathrm{CDB}^{+} \mathrm{T}$ cells in response to MIP-la and MIP-1b. Science 26, 355-358.

19. Wolpe, S.D., Davatelis, G., Sherry, B., Beutler, B., Hesse, D.G., Nguyen, H.T., Moldawer, L.L., Nathan, C.F., Lowry, S.F., Cerami, A. (1988) Macrophages secrete a novel heparin-binding protein with inflammatory and neutrophil chemokinetic properties. J. Exp. Med. 167, 570-581.
20. Rot, A., Krieger, M., Brunner, T., Biechoff, S.C., Schall, T.J., Dahinden, C.A. (1992) RANTES and macrophage inflammatory protein $l \alpha$ induce the migration and activation of normal human eosinophil granulocytes. J. Exp. Med. 176, 1489-1495.

21. Dahinden, C.A., Geiser, T., Brunner, T., von Tschamer, V., Caput, D., Ferrara, P., Minty, A., Baggiolini, M. (1994) Monocyte chemotactic protein 3 is a most effective besophil- and cosinophil-activating chemokine. J. Exp. Med. 179, 751-760.

22. Jose, P.J., Griffiths-Johnson, D.A., Collins, P.D., Walsh, D.T., Moqbel, R., Totty, N.F., Truong; O., Hsuan, J.J., Williams, T.J. (1994) Eotaxin: a potent cosinophil chemoattractant cytokine detected in a guinea pis model of allergic airways inflammation. J. Exp. Med. 179, 881-887.

23. Watson, M.L., Smith, D., Boume, A.D., Thompeon, R.C., Westwick, J. (1994) Cytokines contribute to airway dysfunction in antigen-challenged guinea piga: inhibition of airway hyperreactivity, pulmonary cosinophil accumulation, and tumor necrosis factor generation by pretreatment with an interleukin-1 receptor antagonist. Am. J. Respir. Cell Mol. Biol. 8, 365-369.

24. Lukacs, N.W., Strieter, R.M., Chensue, S.W., Widmer, M., Kunkel, S.L. (1995) TNFQ mediates recruitment of neutrophils and eosinophils during airway inflammation. J. Immunol. 154, 5411-5417.

25. Bradding, P., Feather, I.H., Howarth, P.H., Mueller, R., Roberts, J.A., Bews, J.P., Hunt, T.C., Okayama, Y., Heusser, C.H., et al. (1992) Interleukin 4 is localized to and released by human mast cells. J. Exp. Med. 176 , 1381-1386.

26. Brown, M.A., Pierce, J.H., Watson, C.J., Falco, J., Ihle, J.N., Paul, W.E (1987) B cell stimulatory factor-1/interleukin-4 mRNA is expresced by normal and transformed mast cells. Cell 50, 809-818.

27. Schleimer, R.P., Sterbinsky, S.A., Kaiser, J., Bickel, C.A., Klunk, D.A., Tomioka, K., Newman, W., Luscinskas, F.W., Gmbrone, M.A., Jr., McIntyre, B.W., Bochner, B.S. (1993) IL-4 induces adherence of human eosinophils and basophils but not neutrophils to endothelium. Aseociation with expression of VCAM-1.J. Immunol. 148, 1086.

28. Lukacs, N.W., Strieter, R.M., Chensue, S.W., Kunkel, S.L. (1994) Interleukin-4-dependent pulmonary eosinophil infiltuation in a murine model of asthma. Am. J. Respir. Cell. Mol. Biol. 10, 526-532.

29. Bruseclle, G.G., Kipe, J.C., Travernier, J.H., van der Heyden, J.G., Cuvelier, C.A., Pauwels, R.A., Bluethmann, H. (1994) Attenuation of allergic ainway inflammation in IL 4 deficient mice. Clin. Exp. Allergy 24, 73-80.

30. Schweizer, R.C., Welmers, B.A.C., Rasijmakers, J.A.M., Zanen, P., Lammers, J.W.J., Koenderman, L. RANTES- and Interleukin-8-induced responses in normal human cosinophils: effects of priming with interleukin-5. Blood 83, 3697-3704.

31. Lukacs, N.W., Strieter, R.M., Shaklee, C.L., Chensue, S.W., Kunkel, S.L. (1995) Macrophage inflammatory protein-la influences eosinophil recruitment in antigen-specific airway inflammation. Eur. J. Immunol. 25, 245-251.

32. Holgate, S.T. (1988) Mast cells, mediators and disease. London: Klurg Academic Publishers.

33. Galli, SJ., Gordon, J.R., Worshal, B.K. (1991) Cytokine production by mast cells and basophils. Curr. Opin. Immunol. 3, 865-873.

34. Selvan, R.S., Butterfield, J.H., Krangel, M.S. (1994) Expreasion of multiple chemokine genes by a human mast cell leukemia. J. Biol. Chem. 269, 13893-13898. 